\title{
Recovery intervention of two theatres in Basilicata (Italy): history and techniques
}

\author{
A. Guida, I. Mecca \& A. Pagliuca \\ Department of European and Mediterranean Cultures: Architecture, \\ Environment, Cultural Heritage (DiCEM), University of Basilicata, Italy
}

\begin{abstract}
The need, more and more frequently, for making recovery interventions as well as the technological, structural and functional adaptation of built heritage often collides with the lack of knowledge of its historical, cultural and architectural values. This work is developed on a revaluation assumption of two theatres in Basilicata (Italy), located respectively in the old town centers of Matera and Potenza. Built in the first half of XX century, they represent the first evidence of "Modern Architecture" (realized using concrete), in which the testing of techniques and materials will contribute to define the unique forms and solutions of the building; in fact, they represent the first examples of a new construction technique that, at the time, began to be introduced also in Basilicata. Furthermore, they represent emblematic examples of architecture for the spectacle on which to perform hypothesis of recovery interventions, both for their localization and architectural and/or structural conformation and for materials and construction techniques used. The scientific approach has been articulated, previously, in the data acquisition - needed to perform a diagnostic evaluation; then, in a proposal for architectural and material recovery intervention, through the evaluation of the building condition and the identification of the construction and techniques characteristics. Through a specific knowledge of the building structure, its state of deterioration (pointing out the causes that have determined the decay), it has come to an "operating" definition of the interventions that can be performed. In fact, the "reading" of the built environment cannot be separated from a suitable and methodological appropriation of construction techniques as well as "environmental variables"
\end{abstract}


involved in the life cycle of the building, especially if it has been part of the fabric of the city as well as of the social and cultural life of the community.

Keywords: modern architecture, concrete, methodological approach, construction techniques and technology.

\section{Introduction}

In recent decades, the architectural heritage of the modern movement seems to be more at risk than during any other period. This built inheritance embodies the dynamic spirit of the industrial age. At the end of the 1980s, many modern masterpieces had already been demolished or changed beyond recognition. This was mainly due to the fact that many were not considered to be elements of heritage, that their original functions have substantially changed and that their technological innovations have not always endured long-term stresses. A thorough research of built heritage enables understanding of the evolution of design philosophies and underlying cultural meanings and messages, artistic and functional qualities, and engineering achievements. A detailed knowledge of building materials, construction techniques, environmental services, external impacts and internal impacts of use or disuse assist in identifying the problems affecting buildings and defining a methodological approach for interventions. The research objective is to provide new qualitative information on the strength of reinforced concrete structures of a building by using innovative, non-invasive testing techniques. The case studies are two theatres in Basilicata. The confluence of the local architectural styles (vernacular and academic) and the emerging aesthetic of reinforced concrete is explored to outline the context that influenced the building design. The research methodology includes (a) the context in which the buildings were designed, (b) their history, (c) building technologies used, (d) non-invasive testing of the reinforced concrete structures, (e) the analysis of the test results and (f) the conclusions. Testing methods could be "destructive", as they require a local removal of material, or "nondestructive", i.e. they do not affect the structure. A sclerometer test, an ultrasonic test and their combined use, called SonReb (SONic + REBound), are "nondestructive" tests on reinforced concrete. The combined tests are a very useful method for assessing the concrete strength and to reduce the possibility of errors that can happen if the tests are not combined, as it has been noticed that the humidity content of a structural element can influence the sclerometer index and the ultrasound speed. The combined method requires shorter time to obtain the results.

\section{2 “Modern" architecture}

In Italy, on the contrary on what happened in the rest of Europe in the late XIX century, for new buildings construction was used traditional techniques and materials, with load-bearing masonry, horizontal elements in wood or a vaulted roof and foundations realized in stone. In the early decades of the XX century, in Italy there is a slow and static renewal of the architectural knowledge that, on the 
contrary, constitutes a very important movements in other parts of Europe. In fact, in Europe the implementation of innovation in the construction sector was a prerequisite for the use of new materials and technologies, including reinforced concrete system; but in Italy, in the first three decades of the XX century, the new theoretical concepts will be timidly set out in the various handbook with almost no being achieved in the implementation of works and building construction. In fact, this handbook, while looking enthusiastically to the first experiments on reinforced concrete, consider the concrete as other structural elements and limit its application to the replacement of parts of the building; there was, therefore, the impossibility to grasp the real revolutionary possibility using this material. Only later there will be a slow renewal in the construction sector due to the use of new machinery and equipments in the building yard as well as for the introduction of new processing in the industries that produces building materials and components; in fact, the ornaments and decorations are more simple and give way to stone or ceramic materials, of easier installation, as well as the wall thickness is reduced to disappearance of the load-bearing function and assert new brick elements lightened by holes. In the years, the artificial stone elements slowly take the place of the natural ones, some structural elements, such as flat arch, arches, vaults and wooden floors are replaced with new building systems, at first, made of iron and subsequently of reinforced concrete. From the wooden floors gave way to mixed beams made of steel with secondary structures and wooden planks; then, the horizontal structures was made of steel and structures completed in little vaults, in natural or artificial stone, and, finally, when this construction system was well established in most part of Europe, the horizontal structures was realized in brick and cement slabs as well as in reinforced concrete slabs. The reinforced concrete structures allow a revolution in the field of public and private construction sector; in fact, "[...] they allowed the construction of large-scale environments and very large surface and an elevation of the building to monumental heights, while maintaining a quickness of constructive realization" [1].

\section{The used methodology}

The investigative techniques for concrete are also classified in two defined macro-categories ("destructive" and "non-destructive"). The former are based on the extraction of concrete samples to undertake compressive tests and represent the most reliable instrument for assessing the mechanical properties of concrete. The second investigative typology, the non-destructive tests, can be further subdivided in: really "non-destructive" investigations and "partially destructive" investigations [2, 3]. The SonReb method, as mentioned in the previous paragraph, allows a qualitative determination of the concrete resistance4 through the cross-examination of the values of the speed of ultrasound waves and the values of sclerome-tric bounce. This investigation method is standardised by RILEM (The International Union of Testing and Research Laboratories for Materials and Structures) Recommendations 43 CND - EN 13791:2007, the EC regulation 1-2010 UNI EN 12504-2:2001, ASTM 
C597, UNI EN 12504-4:2005, the Test Report CUR 69, the standards UNI 7997, UNI 9524 and UNI 83308. The SonReb Method (Sonic+Rebound) uses the combined results provided by the above described tests that incorporate a useful instrument for assessing the resistance of concrete [4], enabling the elimination of errors, at least partly, that appear when the two investigation methods are separately applied. This method, in fact, allows reducing the errors made when the sclerometric and ultrasound tests are undertaken separately [5]. SonReb method, therefore, allows a quick and an economic way to obtain reliable qualitative results on the resistance of in situ concrete [6]. The application of Sonreb method requires the evaluation of values of ultrasonic speed "V" and "S" rebound index, from which it is possible to get the "Rc" concrete resistance using expressions as:

$$
\begin{gathered}
\mathrm{Rc} 1=9,27 * 10-11 * \mathrm{~S} 1,4 * \mathrm{~V} 2.6 \text { (RILEM [7]) } \\
\mathrm{Rc} 2=8,06 * 10-8 * \mathrm{~S} 1,246 * \mathrm{~V} 1,85 \quad \text { (Gasparik [8]) } \\
\mathrm{Rc} 3=1,2 * 10-9 * \mathrm{~S} 1,058 * \mathrm{~V} 2,446 \quad \text { (Di Leo and Pascale [9]) }
\end{gathered}
$$

where "Rc" is the cubic compressive resistance in $\left[\mathrm{N} / \mathrm{mm}^{2}\right]$, " $\mathrm{S}$ " is the rebound index and " $\mathrm{V}$ " is the ultrasonic speed in $[\mathrm{m} / \mathrm{s}]$. The evaluation of concrete resistance can also carry out using diagrams (using " $V$ " and " $S$ " as Cartesian coordinates) containing isoresistance curves. Those curves are obtained by the expressions above. This qualitative appraisal of the resistance of concrete can be made even by using the graphs (Figure 1) which show a series of isoresistance curves in the plane V-S (obtained from the above analytic expressions) and which refer to the tests undertaken on standardised samples in a laboratory. Although it appears absolutely necessary to analyse a wider range of cases, the above methodological investigation approach, based on the comparative analysis of the two described test campaigns, suggests several important considerations regarding the modality of investigation and the interpretation of results, demonstrating the need for establishing general investigation criteria: more than defining in a strict manner the number of tests that should be undertaken, it would be necessary to preset the level of significance to be achieved.

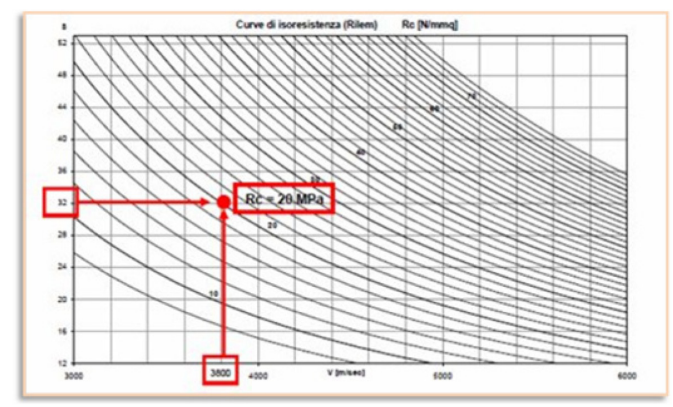

Figure 1: Example of isoresistance curves - RILEM NDT 4 recommendations. 
SonReb method, therefore, allows a quick and an economic way to obtain reliable qualitative results on the resistance of in situ concrete, permitting to carry out effective preliminary evaluation required for the explanation (and further design) of the restoration interventions to be undertaken on the investigated architecture.

\section{Case studies: “Ariston" Cinema in Potenza and "Duni" Theatre in Matera}

The analysis undertaken so far and the discussion on tentative diagnoses need to be applied on site and require a validation of obtained data. Therefore, two case studies were selected, two architectural examples that represent two significant moments in the architectural culture of the places in which they emerged. Their importance is fundamentally linked to what they represent in the architectural debate on techniques and technologies regarding the construction sector at the start of the 20th century. The buildings are the "Ariston" Cinema in Potenza (designed by the engineer Augusto Magno and built between 1954 and 1955) and the "Duni" Theatre in Matera (designed by the architect Ettore Stella and built between 1946 and 1949). These two buildings, although of different time of construction, form and size, finishes and materials, technological and structural systems, are linked by being both among the first realisations in reinforced concrete in the places in which they were built. In fact, they represent a synthesis of what the debate in architectural field was in those years and in specific social, cultural and economic context in which the two buildings were conceived, designed and, finally, built.
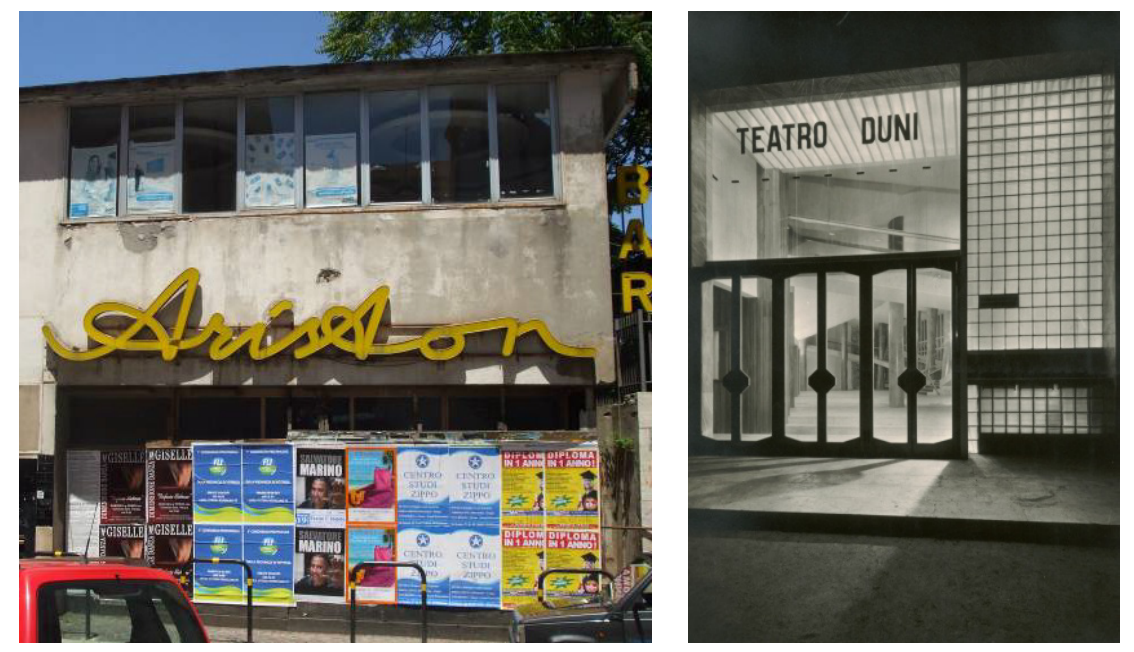

Figure 2: “Ariston” Cinema in Potenza and "Duni” Theatre in Matera. 


\subsection{The Ariston Cinema: analysis and results}

The “Ariston” Cinema was designed by the engineer Augusto Magno and built between 1954 and 1955 in the city centre of Potenza, in the southern part of Italy. The contrast between that building - realized in reinforced concrete - and the surrounding building, built in XVII-XVIII century, highlights an historical transition from traditional building techniques to new technologies, which will change the architecture of the city. The "Ariston" Cinema, differently from other similar structures, is located in a particular configuration, on a natural slope; its complex structure, following the ground layout, adapts to it without changing it. The building, built in a narrow and elongated lot, has a rectangular shape, in which it enters various irregular volumes. The building functional organization, clear and simple, allows the identification of the interior space, needed to perform the film activities, such as the lobby, the room, the projection booth as well as the scene in which took place the screen, now demolished. The Cinema has about 700 seats, divided into stalls (about $330 \mathrm{~m}^{2}$ ) and balcony (about $220 \mathrm{~m}^{2}$ ). The building was built in reinforced concrete structure, using the Hennebique system [10]; the frame structure was realized using pillars and beams. While the horizontal elements were realized in brick and concrete slab as well as reinforced concrete slabs.

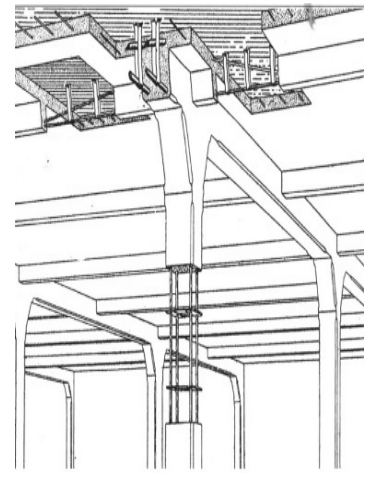

Figure 3:

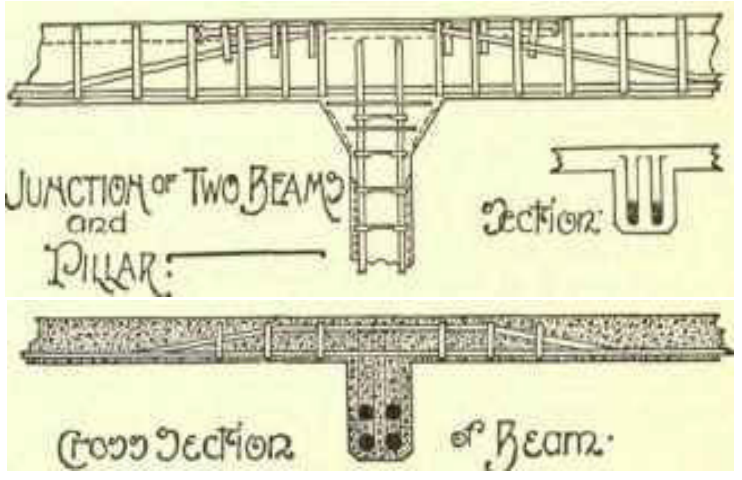

Hennebique’s construction system.

Hennebique introduced a new construction system that united the resistance and compression characteristics of concrete with the capability of steel to resist tensile forces by optimising the placement of bars within the concrete components (similarly to the braces, the lower bars are folded at $45^{\circ}$ and extended to the upper bars of a beam where the inversion of moment occurs). Hennebique's system, therefore, allows the complete construction of a load bearing structure of reinforced concrete which includes the foundation (footings or inverted beams or slabs), columns, principal beams, secondary beams and slabs; columns (square, rectangular or polygonal sections) and beams envisaging even the introduction of a new element in the system of longitudinally placed bars: stirrups (the twin vertical braces made of iron whose function was to hinder 
diagonal forces in a bending component). To operate the tests, it was enough to identify 6 survey points including 3 in the top floor (atrium and gallery) and 3 on the lower level (stalls); this choice was defined by the geometry and size of the structure. The atrium, which appears with a regular grid of circular columns with constant spacing, has an area of about $175 \mathrm{~m}^{2}$; it was sufficient to determine a single pillar ( $\left.\mathrm{Pa} \_1\right)$. The gallery, with a surface area of about $210 \mathrm{~m}^{2}$, has a symmetrical plan; it have been chosen 2 symmetrical pillars (Pg_2, Pg_3), to verify the homogeneity of the structure. Finally, in the stalls, with a surface of $330 \mathrm{~m}^{2}$, were selected 3 pillars, characterized by a different geometry; it was chosen a variable section pillar (Pp_4), a rectangular shape pillar (Pp_5) and, the last one, with rectangular section, in which one dimension is approximately onethird of the other (Pp_6). The tests were undertaken in April 2012. In this case, the number of ten values per each test was adopted; their average value was considered as a typical example. The rebound index on the analyzed pillars were: on (Pa_1) equal to 34.8, on (Pg_2) equal to 49.5, on (Pg_3) equal to 40.5, on (Pp_4) equal to 39.4, on (Pp_5) equal to 40.8, on (Pp_6) equal to 36.3. The results obtained show that the rebound index of the first investigated element $\left(\mathrm{Pa} \_1\right)$ and of the second one (Pg_2), diverges significantly from the value obtained from the average of the indices of rebound in 6 tests. Through the ultrasound test on each pillar were calculated values of the average speed of wave propagation inside the pillar. Particular attention it was given to the grip between the instruments and the surface of the investigated component. Different mediums are used to achieve better grip between the instruments and the surface. The ultrasound tests have returned average values of the ultrasound speed between a minimum value of $2190 \mathrm{~m} / \mathrm{s}$ and a maximum value of $3505 \mathrm{~m} / \mathrm{s}$, as the table below shows:

Table 1: $\quad$ Ultrasound test results.

\begin{tabular}{|c|c|c|}
\hline \multicolumn{2}{|c|}{ Structural Element } & \multirow{2}{*}{$\begin{array}{c}\text { Ultrasound Test } \\
\text { Average Speed } \\
(\mathrm{m} / \mathrm{s})\end{array}$} \\
\hline Code & $\begin{array}{l}\text { Dimension } \\
\text { (cm) }\end{array}$ & \\
\hline Pa_1 & $\mathrm{d}: 30 \div 90$ & 2190 \\
\hline Pg_2 & $45 \times 50$ & 3382 \\
\hline Pg_3 & $40 \times 50$ & 2984 \\
\hline Pp_4 & $\begin{array}{l}50 \div 80 \times \\
70 \div 140\end{array}$ & 3505 \\
\hline Pp_5 & $40 \times 65$ & 2290 \\
\hline Pp_6 & $70 \times 25$ & 3367 \\
\hline
\end{tabular}

Comparing the results obtained from ultrasound tests with the studies provided by the technical literature, the values refer to concrete which has been placed under conditions that have been defined as bad; in fact the average speed is less than $3000 \mathrm{~m} / \mathrm{s}$ (Pa_1, Pp_3, Pg_5), that is the minimum acceptable value in the literature. Finally, it was compared the results by using the SonReb method to obtained values of the resistance of the reinforced concrete, as Table 2 shows. 
Table 2: $\quad$ Obtained values of the resistance of the reinforced concrete.

\begin{tabular}{|c|c|c|c|c|c|c|c|}
\hline \multirow[t]{2}{*}{ Code } & \multirow{2}{*}{$\begin{array}{l}\text { Rebound } \\
\text { index }\end{array}$} & \multirow{2}{*}{$\begin{array}{c}\text { Average } \\
\text { Speed }\end{array}$} & \multicolumn{5}{|c|}{$\mathrm{Rc}$ [MPa] } \\
\hline & & & Rilem & Gasparik & Pascale & $\begin{array}{c}\text { Del } \\
\text { Monte }\end{array}$ & Giacchetti \\
\hline Pa_1 & 34.8 & 2190 & 6.45 & 10.14 & 7.58 & 10.60 & 5.35 \\
\hline Pg_2 & 49.5 & 3382 & 37.76 & 35.21 & 31.94 & 32.92 & 27.19 \\
\hline Pg_3 & 40.4 & 2984 & 17.24 & 21.20 & 18.41 & 20.76 & 14.31 \\
\hline Pp_4 & 39.4 & 3505 & 26.11 & 28.31 & 27.38 & 27.04 & 21.68 \\
\hline Pp_5 & 40.8 & 2290 & 9.05 & 13.43 & 10.01 & 13.68 & 7.51 \\
\hline Pp_6 & 36.3 & 3367 & 20.97 & 23.76 & 22.76 & 23.04 & 17.41 \\
\hline
\end{tabular}

The obtained results show how the different expressions, used to calculate the concrete resistance with a SonReb method, provide values almost comparable; it is clear, in fact, that it cannot speak of homogeneity of the investigated concrete, as, in the first and fifth pillar, the results are lower than those of the other investigated pillars as well as the second pillar is characterized by higher values.

\subsection{The Duni Theatre: analysis and results}

The Duni Theatre was the first public work designed by Stella and it was done with enthusiasm for his town. This was the first work built entirely in reinforced concrete in Matera. The young architect was aware of the construction difficulties with this new material, above all for the Materan workers who, although experts in working with tufa, had little or no experience working with reinforced concrete. Altogether, the project provided for a theatre with 1049 seats, divided into stalls and balcony; the cash register was placed in the centre of the large foyer, where the doors open at the back of the stalls. This planning solution allowed the use of the entrance hall as a grand "foyer" for the theatre spectators and created a special unity between the theatre and the lobby. There are two ramps facing each other, which lead from the lobby to the balcony at the extreme ends of a corridor which divides the balcony into two sections: the upper and lower balcony, looking out over the stalls. The structure was built entirely of reinforced concrete; the ground conditions (an area of clay sediment and a water table) requiring the structural engineer to opt for a foundation of reinforced concrete inversed beams. The concrete was prepared on site combining the cement, coming from Bari, together with the iron for the reinforcement bars, sand from the Bradano River and rubble from local quarries. The perimeter walls of solid brick, about $50 \mathrm{~cm}$ thick, are fire resistant and run independently of the supporting structure which is built from long, visible, circular-sectioned columns and cast square-sectioned beams in reinforced cement. The stage is enclosed in a self-supporting tufa wall, $80 \mathrm{~cm}$ thick. The mixed-structure lofts are built from concrete beams and perforated bricks. The internal vault surface is finished off with a single layer of plaster, while the external vault surface is finished off with different materials such as marble and tiles, depending on the destined use of each space. The roof structure spans the entire space with a large vault consisting of arched reinforced concrete beams [11]. Together with these spatial and 
architectural components, there are technological aspects related to the acoustics such as the reflection and the absorption characteristics of the lateral walls which eliminate distortion and concentration of sound, and the finishes whose formal and material design confers organic unity and a "strong" image to a deliberately “modern" work [12]. The tests were undertaken in March 2011 (external environmental conditions: temperature between $6-12^{\circ} \mathrm{C}$ and air humidity 45 $69 \%)$. In this case also, the number [13] of ten values per each test was adopted; their average value was considered as a typical example. Following the calibration of the instruments (by using an anvil for the sclerometer and a sample test for ultrasound tests), three different investigation points were selected for each component: at $0.50 \mathrm{~m}$, at $1.00 \mathrm{~m}$ and at $1.50 \mathrm{~m}$ from the floor. Therefore, the selection was made according to the easiness of the execution of the tests and by investigating the columns at the points of major stress (close to the base) and having assumed an uniformity of the loads and the imposed loads distribution (due to regularity and modularity of the structure) and a homogenous condition of load (also due to the absence of any cracks that would induce different thinking). The obtained results - as the tables show - highlight the homogenous results in relation to the type of the component geometry. The round columns have returned values of the sclerometric bounce index (average value of the ten measurements for each point) between 35.55 and 39.35 uniformly distributed on the surface (i.e. independently of the number of the investigation tests). The ultrasound tests have returned average values of the ultrasound speed between a minimum value of $3405.90 \mathrm{~m} / \mathrm{s}$ and a maximum value of $3480.85 \mathrm{~m} / \mathrm{s}$. Comparing the results by using the SonReb method, the values of the resistance of concrete were obtained from a minimum value of $18 \mathrm{MPa}$ to a maximum value of $21 \mathrm{MPa}$. The columns with the elliptical profile (and with a smaller section at mid-height) have returned the sclerometric bounce index (average value of the ten measurements taken for each point) between 36 and 39.75 uniformly distributed on the surfaces (i.e. independently of the number of the investigation tests). The ultrasound tests have returned average values of the ultrasound speed between a minimum value of $3118.00 \mathrm{~m} / \mathrm{s}$ and a maximum value of $3188.60 \mathrm{~m} / \mathrm{s}$. Comparing the results by using the SonReb method, the obtained values of the resistance of the reinforced concrete are between a minimum value of $15 \mathrm{MPa}$ and a maximum value of $17 \mathrm{MPa}$. The tests run on the structure of the Duni Theatre have shown a substantial homogeneity for the values obtained for each level investigated in function of the type of geometry of the element itself (the round columns of the stalls and/or the elliptical shapes (and tapered) for the ramps in the lobby and for the structure of the balcony); for the first type (round columns), the sclerometric tests showed an average rebound index value to be between 35.55 and 39.35. Compression resistance values for cubes of concrete have been reported in the table provided by the equipment manufacturer and in numerous studies found in the literature, giving values between $300 \mathrm{~kg} / \mathrm{cm}^{2}$ and $390 \mathrm{~kg} / \mathrm{cm}^{2}$. For the elliptical type of column (tapered), the average rebound index value is between 36 and 39.75. Compression resistance values for cubes of concrete have been reported in the table provided by the equipment manufacturer and in numerous studies found in the literature, 
giving values between $310 \mathrm{~kg} / \mathrm{cm}^{2}$ and $390 \mathrm{~kg} / \mathrm{cm}^{2}$. While the ultrasound tests show for the first type (round columns) the average ultrasound speed values to be between a minimum of $3405.90 \mathrm{~m} / \mathrm{s}$ and a maximum of $3480.85 \mathrm{~m} / \mathrm{s}$. Comparing the results obtained from ultrasound tests with the studies provided by the technical literature, the values refer to concrete which has been placed under conditions that have been defined as acceptable; for the elliptical type column (tapered) the ultrasonic tests show average ultrasound speed values to be between a minimum of $3118.00 \mathrm{~m} / \mathrm{s}$ and a maximum of $3188.60 \mathrm{~m} / \mathrm{s}$. Comparing the results obtained from ultrasonic tests with the studies provided by the technical literature, the values refer to concrete which has been placed under conditions that have been defined as acceptable. The evident non-homogeneity of the results obtained for each of the two types of columns investigated can - in all probability - be attributed, above all, to the non-homogeneity of the surface finishing layer, which prevents the proper passage of waves within the structure. Finally, comparing the results using the SonReb method for the first type, (round columns), characteristic resistance values for concrete are obtained which go from a minimum of $18 \mathrm{Mpa}$ to a maximum of $21 \mathrm{Mpa}$. These give compression resistance values for concrete of between $180 \mathrm{~kg} / \mathrm{cm}^{2}$ and $210 \mathrm{~kg} / \mathrm{cm}^{2}$, lower (almost half) of what would have been obtained using each test singularly. For the elliptical type of column (tapered), characteristic resistance values for concrete are obtained which go from a minimum of $15 \mathrm{Mpa}$ to a maximum of $17 \mathrm{Mpa}$. These give compression resistance values for concrete of between $150 \mathrm{~kg} / \mathrm{cm}^{2}$ and $170 \mathrm{~kg} / \mathrm{cm}^{2}$, lower (almost half) of what would have been obtained using each test singularly.

\section{Conclusions}

The study was carried out within the framework of the recovery of Modern Architecture, such as Basilicata (Southern part of Italy), that has not known a real stage of industrialization. The Recovery Project - that takes particular care in the methodological application of the diagnostic phase - cannot leave out of consideration the necessity of a careful and timely monitoring of building conditions. The carried out tests are the first and simplest analysis for a qualitative assessment; it is necessary to classify the structure regarding the following consolidation procedures. The recovery and conservation project, as well as an "indispensable" transformation of this kind of heritage, must be in that evaluations - of feasibility and suitability, both economic and practice - the basis for a "suitable choice" of recovery intervention.

\section{References}

[1] Astrua, G., Manuale completo del capomastro assistente Edile, Editore Ulderico Hoepli, Milano, p. 298, 1958.

[2] Pucinotti, R., Patologia e Diagnostica del Cemento armato (Indagini non Distruttive e Carotaggi nelle Opere da Consolidare), Dario Flaccovio Editore Book, 2006. 
[3] Masi, A., La stima della resistenza del calcestruzzo in situ mediante prove distruttive e non distruttive. Il Giornale delle Prove non Distruttive Monitoraggio Diagonstica, n.1, 2005.

[4] Giochetti, R. and Lacquaniti, L., Controlli non distruttivi su impalcati da ponte in calcestruzzo armato, Nota Tecnica 04, Università degli Studi di Ancona, Facoltà di Ingegneria, Istituto di Scienza e Tecnica delle Costruzioni, 1980.

[5] Braga, F., Dolce, M., Masi. A. and Nigro, D., Valutazione delle caratteristiche meccaniche dei calcestruzzi di bassa resistenza mediante prove non distruttive, L'Industria Italiana del Cemento, n. 3, pp. 200-212, 1992.

[6] Di Leo, A. and Pascale, G., Prove non distruttive sulle costruzioni in cemento armato, Convegno Sistema Qualità e Prove non Distruttive per l'affidabilità e la sicurezza delle strutture civili, Bologna - SAIE, pp. 2536, 1994.

[7] RILEM, Recommendations for in situ concrete strength determination by combined non destructive methods, Compendium of RILEN Technical Recommendations, NDT 4, E\&FN Spon, London, 1993.

[8] Gasparik, J., Prove non distruttive nell'edilizia, Quaderno didattico AIPnD, Brescia, 1992.

[9] Di Leo, A. and Pascale, G., Prove non distruttive sulle costruzioni in c.a., Il giornale delle prove non distruttive, n. 4. 1994.

[10] Nelva, R. and Signorelli, B., Avvento ed evoluzione del calcestruzzo armato in Italia: il sistema Hennibique, Aitec Associazione Italiana Tecnico Economia del cemento, Edizioni di Scienza e Tecnica, Milano, 1990.

[11] Acito, L., "Il Cinema-Teatro Duni di Matera. Un'architettura moderna da tutelare", Edizioni Librìa, Melfi, 1999.

[12] Guida, A., Pagliuca, A. and Dimitrijevic, B., Reinforced Concrete Condition Assessment in Architectural Heritage. The Lion Chambers (Glasgow, UK) and the Theatre E. Duni (Matera, Italy), edito da CUES - Cooperativa Universitaria Editrice Studi, Fisciano (SA), Italy, 2011.

[13] OPCM 3274/2005, Ordinanza del Presidente del Consiglio dei Ministri of 20 March 2003 "Principal elements regarding the general criteria for seismic classification of the national territory and of the technical standards for construction in seismic areas", revised by Gruppo di Lavoro istituito dal Dipartimento di Protezione Civile. 